\title{
UM BREVE ESTUDO HISTÓRICO-ANALÍTICO DA LEI DE HUME
}

- RESUMO: A Lei de Hume, pela qual um dever ser não pode resultar de um ser, e a sua recíproca, pela qual um ser não pode resultar de um dever ser, ocupam posições proeminentes nas discussões de metaética. Neste trabalho mostrarei relações lógicas entre distintas formulações da Lei de Hume e da sua recíproca. Também mostrarei como essas formulações estão relacionadas a teses sustentadas por importantes pensadores como Poincaré, Nelson, Jörgensen e Hare.

- PALAVRAS-CHAVE: Lei de Hume; recíproca da Lei de Hume; metaética; Poincaré; Nelson; Jörgensen; Hare.

\section{Introdução}

De proposições retiradas somente de fatos não é jamais possível tirar nenhuma conclusão prática. A enunciação A preservação da sociedade depende disso não pode levar ao imperativo faça isso, exceto se for mediada por outra enunciação, qual seja: a sociedade deve ser preservada. Da mesma forma, Isso irá custar a sua vida não pode levar diretamente a não faça isso: somente pelo intermédio de um desejo ou por um reconhecido dever de autopreservação. O Inovador tenta chegar a uma conclusão de teor imperativo a partir de uma premissa de teor indicativo, e, mesmo que siga tentando por toda a eternidade, não vai conseguir, pois seria impossível. (Lewis, 2005, p. 29-30)

A epígrafe acima, retirada do livro A abolição do homem de C. S. Lewis, enuncia uma tese sobre o problema de que trato neste trabalho, um proble-

1 Professor Adjunto do Departamento de Filosofia e do Programa de Pós-Graduação em Filosofia da Universidade Federal de Santa Maria-UFSM. Artigo recebido em jun/06 e aprovado para publicação em nov/06 
ma filosófico dos mais importantes para o cotidiano das pessoas, magistralmente exposto por Hume. Ao término do Livro III, Parte I, Seção I do Tratado da natureza humana, Hume observa o seguinte acerca das relações lógicas entre o domínio do dever ser e o domínio do ser:

Em todo sistema de moral que até hoje encontrei, sempre notei que o autor segue durante algum tempo o modo comum de raciocinar, estabelecendo a existência de Deus, ou fazendo observações a respeito dos assuntos humanos, quando, de repente, surpreendo-me ao ver que, em vez das cópulas proposicionais usuais, como é e não é, não encontro uma só proposição que não esteja conectada a outra por um deve ou não deve. Essa mudança é imperceptível, porém da maior importância. Pois, como esse deve ou não deve expressa uma nova relação ou afirmação, esta precisaria ser notada e explicada; ao mesmo tempo, seria preciso que se desse uma razão para algo que parece inteiramente inconcebível, ou seja, como essa nova relação pode ser deduzida de outras inteiramente diferentes.(Hume, 2000, p. 509)

Esta passagem, mesmo se ignorarmos seu autor e seu contexto, parece admitir uma única interpretação: o autor critica o modo pelo qual o que pertence ao domínio do dever ser é derivado do que pertence ao domínio do ser, deixando em aberto a questão sobre a própria possibilidade de uma derivação desse tipo. Esta interpretação é, por exemplo, a interpretação fornecida por Rabossi (2002, p. 372). Entretanto, há uma tese mais restritiva do que a tese veiculada pela interpretação acima mencionada, usualmente associada a Hume e à passagem supracitada: o que pertence ao domínio do dever ser nunca pode ser deduzido do que pertence ao domínio do ser, ou seja, esta tese, tradicionalmente denominada Lei de Hume, impõe uma barreira lógica entre o domínio do dever ser e o domínio do ser.

A Lei de Hume e a sua recíproca, a tese de que o que pertence ao domínio do ser nunca pode ser deduzido do que pertence ao domínio do dever ser, são os correlatos, no plano lógico, de teses de Moore, no plano conceitual, sobre a impossibilidade de definir o que pertence ao domínio do dever ser por intermédio do que pertence ao domínio do ser e definir o que pertence ao domínio do ser por intermédio do que pertence ao domínio do dever ser, respectivamente. Ambas, Lei de Hume e a sua recíproca, ocupam posições proeminentes nas discussões de metaética. Kelsen (1986, p. 77), por exemplo, é enfático ao sustentar essa barreira lógica, tanto em um sentido como em outro: "Visto que algo pode ser, o qual não é devido numa norma, e algo pode ser devido numa norma, o qual - em realidade - não é, não pode disto resultar que algo é, que algo deve ser, e disto não pode resultar que algo deve ser, que algo é."

O estabelecimento de barreiras lógicas não é uma prática exclusiva do domínio normativo. Restall e Russell (s/d), por exemplo, enunciam e discutem os seguintes princípios sobre barreiras lógicas: 
a) Lei de Russell, conforme a qual uma proposição geral não pode resultar de proposições particulares;

b) Segunda Lei de Hume, conforme a qual uma proposição sobre o futuro não pode resultar de proposições sobre o passado ou o presente;

c) Lei de Kant, conforme a qual uma proposição apodíctica não pode resultar de proposições assertóricas.

Restall e Russell (s/d) também observam que formulações imprecisas destes princípios, formulações nas quais as classes de proposições sobre as quais incide a barreira lógica são delimitadas de modo vago, admitem a construção de contra-exemplos. Eles destacam esse ponto com um exemplo emprestado de Prior: seja A um juízo não moral e B um juízo moral; caso se considere a disjunção de $\mathrm{A}$ e B um juízo moral, a derivação da disjunção de $\mathrm{A}$ e $\mathrm{B}$ a partir da premissa $\mathrm{A}$, por enfraquecimento desta premissa, é um contra-exemplo à Lei de Hume; caso se considere a disjunção de A e B um juízo não moral, a derivação de B a partir da disjunção de A e B e da negação de A, por silogismo disjuntivo, é um contra-exemplo à Lei de Hume!

Meu objetivo, na primeira metade deste trabalho, consistirá em enunciar diferentes formulações que podem ser dadas à Lei de Hume e à sua recíproca. Para evitar casos não interessantes e contra-exemplos óbvios, definirei e utilizarei a noção de "conjunto relevante de premissas para uma dada conclusão".

Na segunda metade deste trabalho, com auxílio de três teses acessórias, mostrarei a relação existente entre as formulações obtidas na primeira metade deste trabalho com teses sustentadas por importantes teóricos da primeira metade do século XX nos campos do Direito e da Moral.

\section{Formulações de barreiras inferenciais entre dever ser e ser}

A eliminação de casos não interessantes ou contra-exemplos óbvios é condição necessária para um tratamento adequado das relações lógicas entre o âmbito do dever ser e o âmbito do ser, por isso sugiro a utilização da seguinte noção de "conjunto relevante de premissas para uma dada conclusão":

DEFINIÇÃO. Um conjunto de premissas é relevante para uma conclusão se e somente se essa conclusão é conseqüência lógica desse conjunto de premissas e não há um subconjunto próprio desse conjunto de premissas tal que essa conclusão é conseqüência lógica desse subconjunto próprio desse conjunto de premissas. 
As quatro formulações seguintes de princípios de barreiras lógicas entre o âmbito do dever ser e o âmbito do ser, enumeradas segundo a ordem de apresentação, têm a forma de juízos hipotéticos, são formulações condicionais de barreiras lógicas, relacionando restrições sobre um conjunto de premissas face à possibilidade ou impossibilidade de uma conclusão pertencente ao âmbito do dever ser:

Se uma conclusão pertence ao âmbito do dever ser, então nenhum conjunto relevante de premissas para essa conclusão tem elementos pertencentes exclusivamente ao âmbito do ser (1).

Se há um conjunto relevante de premissas para uma conclusão cujos elementos pertençam exclusivamente ao âmbito do ser, então essa conclusão não pertence ao âmbito do dever ser (2)

Se uma conclusão pertence ao âmbito do dever ser, então todos os conjuntos relevantes de premissas para essa conclusão têm ao menos um elemento pertencente ao âmbito do dever ser (3).

Se há um conjunto relevante de premissas para uma conclusão que não tem elementos pertencentes ao âmbito do dever ser, então essa conclusão não pertence ao âmbito do dever ser (4).

As quatro formulações seguintes de princípios de barreiras lógicas entre o âmbito do dever ser e o âmbito do ser, enumeradas segundo a ordem de apresentação e em continuidade à enumeração anterior, também têm a forma de juízos hipotéticos, são formulações condicionais de barreiras lógicas, relacionando restrições sobre um conjunto de premissas face à possibilidade ou impossibilidade de uma conclusão pertencente ao âmbito do ser:

Se uma conclusão pertence ao âmbito do ser, então nenhum conjunto relevante de premissas para essa conclusão tem ao menos um elemento pertencente ao âmbito do dever ser (5).

Se há um conjunto relevante de premissas para uma conclusão que tem ao menos um elemento pertencente ao âmbito do dever ser, então essa conclusão não pertence ao âmbito do ser (6).

Se uma conclusão pertence ao âmbito do ser, então todos os conjuntos relevantes de premissas para essa conclusão têm elementos pertencentes exclusivamente ao âmbito do ser (7)

Se há um conjunto relevante de premissas para uma conclusão que tem ao menos um elemento não pertencente ao âmbito do ser, então essa conclusão não pertence ao âmbito do ser (8). 
As relações lógicas entre as formulações acima são as seguintes: a tese da formulação 2 é a contrapositiva da tese da formulação 1, a tese da formulação 4 é a contrapositiva da tese da formulação 3, a tese da formulação 6 é a contrapositiva da tese da formulação 5 , e a tese da formulação 8 é a contrapositiva da tese da formulação 7. Nada se pode dizer, até o momento, sobre as relações lógicas entre as teses das formulações do primeiro bloco de formulações (1 a 4) e as teses das formulações do segundo bloco de formulações (5 a 8). Isso será possível quando introduzir, na próxima seção, algumas teses auxiliares, que, embora sejam bastante plausíveis, não são analíticas.

As duas formulações seguintes de princípios de barreiras lógicas entre o âmbito do dever ser e o âmbito do ser, respeitando as mesmas condições das formulações anteriores quanto à enumeração, são, ao contrário das formulações anteriores, formulações incondicionais de barreiras lógicas entre o âmbito do dever ser e o âmbito do ser:

Não há argumento válido cuja conclusão pertence ao âmbito do dever ser (9).

Não há argumento válido com ao menos um conjunto relevante de premissas para a conclusão que tem ao menos um elemento pertencente ao âmbito do dever ser (10).

\section{As relações entre as formulações e teses sustentadas na literatura filosófica}

Para poder relacionar logicamente as formulações do primeiro bloco de formulações (1 a 4) às formulações do segundo bloco de formulações (5 a 8) e relacionar essas distintas formulações a teses sustentadas na literatura filosófica, utilizarei as três seguintes teses auxiliares, seguindo o padrão de enumeração das formulações anteriores:

Uma premissa (conclusão) pertence ao âmbito do dever ser se e somente se ela não pertence ao âmbito do ser (11)

Se há um conjunto relevante de premissas para uma conclusão cujos elementos pertençam exclusivamente ao âmbito do ser, então todos os conjuntos relevantes de premissas para essa conclusão têm elementos pertencentes exclusivamente ao âmbito do ser (12).

Se há um conjunto relevante de premissas para uma conclusão que tem ao menos um elemento pertencente ao âmbito do dever ser, então todos os conjuntos relevantes de premissas para essa conclusão têm ao menos um elemento pertencente ao âmbito do dever ser (13). 
Na presença da tese 11, a tese da formulação 3 colapsa na tese da formulação 1 , a tese da formulação 4 colapsa na tese da formulação 2 , a tese da formulação 7 colapsa na tese da formulação 5, e a tese da formulação 8 colapsa na tese da formulação 6 . Formam-se, portanto, dois blocos de formulações caracterizados não apenas pelo assunto que as une (a possibilidade ou impossibilidade de conclusão pertencente ao âmbito do dever ser no primeiro bloco, a possibilidade ou impossibilidade de conclusão pertencente ao âmbito do ser no segundo bloco) mas, principalmente, pela tese que as une.

Na presença das teses 11 e 12, a tese da formulação 5 é a recíproca da tese da formulação 4, e a tese da formulação 7 é a recíproca da tese da formulação 2. Além disso, na presença das teses 11 e 13, a tese da formulação 6 é a recíproca da tese da formulação 3 , e a tese da formulação 8 é a recíproca da tese da formulação 1. Portanto, na presença das teses 11, 12 e 13, reforça-se a formação de dois blocos de teses: o bloco da tese subjacente às formulações 1 a 4 e o bloco da tese subjacente às formulações 5 a 8.

Tem-se, além disso, que a tese do bloco de formulações 1 a 4 é conseqüência lógica da tese da formulação 9 , e a tese do bloco de formulações 5 a 8 é conseqüência lógica da tese subjacente à formulação 10.

Os diversos teóricos do Direito e da Moral abaixo relacionados, que desenvolveram suas atividades nos primórdios do estudo sistemático das relações entre Lógica, por um lado, e Direito e Moral, por outro lado, propuseram distintas formulações de teses sobre barreiras lógicas entre o âmbito do dever ser e o âmbito do ser, freqüentemente confundidas com formulações e teses subjacentes a formulações sustentadas por outros pensadores.

Poincaré (apud Jörgensen, 1938, p. 288), por exemplo, sustenta que "de frases no modo indicativo somente frases que também estão no modo indicativo podem ser derivadas por inferência lógica", ou seja, na presença das teses 11 e 12, ele sustenta a tese subjacente à formulação 2. Nelson (apud Jörgensen 1938, p. 289-290) sustenta que "frases imperativas podem ser inferidas de outras frases imperativas" e Hare (1996, p. 30) sustenta que "Nenhuma conclusão imperativa pode ser extraída validamente de um conjunto de premissas que não contenha pelo menos um imperativo". Portanto, eles sustentam, na presença da tese 13, a tese da formulação 3. Hare (1996, p. 29) tem uma segunda formulação segundo a qual "Nenhuma conclusão indicativa pode ser extraída validamente de um conjunto de premissas que não possa ser extraído validamente apenas dos indicativos dentre elas", ou seja, na presença de 12, ele sustenta a tese da formulação 7. Jörgensen (1938, p. 289) sustenta, meramente para fins argumentativos, que "eles [os comandos] são incapazes de figurar como conclusão em inferências lógicas", ou seja, ele sustenta a tese da formulação 9. Jörgensen (1938, p. 289) também sustenta, meramente para fins argumentativos, que "eles [os co- 
mandos] sequer são capazes de figurar como premissas em tais inferências [as inferências lógicas][...]", ou seja, ele sustenta a tese da formulação 10.

\section{Considerações finais}

Encontram-se disponíveis, na literatura filosófica, diversas tentativas de aplicar a Lógica ao Direito e à Moral. Em muitos casos os proponentes rejeitam a aplicação direta da Lógica ao Direito e à Moral, e, em seu lugar, propõem uma aplicação indireta a esses daquela. O procedimento típico consiste em traduzir frases que versam sobre o âmbito do dever ser em frases que versam sobre o âmbito do ser; operar logicamente com as frases que versam sobre o âmbito do ser; e traduzir, pela tradução inversa da anteriormente mencionada, a conclusão assim obtida numa frase que versa sobre o âmbito do dever ser. Esse é um modo cômodo de tratar do Dilema de Jörgensen, suscitado por Jörgensen (1938) e batizado desse modo por Ross (1941), que nos coloca diante das seguintes alternativas ao tratar da aplicação da Lógica ao campo normativo: ou ampliamos a noção tradicional de Lógica de modo a admitir relações de conseqüência lógica envolvendo aquilo que pertence propriamente ao âmbito do dever ser, ou recusamos qualquer possibilidade de aplicação da Lógica ao âmbito do dever ser. Propostas envolvendo uma aplicação indireta resolvem o Dilema de Jörgensen do segundo modo, sem que a escolha desta alternativa impeça completamente a existência de aplicação da Lógica ao campo normativo. Ross (1941) e o primeiro Kelsen (1998), por exemplo, são autores que aceitam esse tipo de aplicação indireta e mostram como fazê-la; no caso de Ross (1941), inclusive, isso pode ser feito de dois modos distintos. Contudo, os passos de tradução efetuados nesse tipo de procedimento nem sempre são devidamente justificados, nem sempre são explicitadas as teses sobre barreiras lógicas que estão envolvidas. Por exemplo, quase nunca há uma justificativa explícita do porquê, após operar logicamente com frases do escopo do ser, é preciso usar a tradução inversa para chegar a uma conclusão do escopo do dever ser. Que assim seja parece natural, mas natural não é o mesmo que justificado. Este trabalho pretendeu contribuir com a tarefa de entender a aplicação indireta da Lógica ao Direito e à Moral ao identificar diferentes teses e formulações de teses sobre barreiras lógicas que podem estar operando nesses processos.

SAUTTER, F. T. A brief historic-analytical study of Hume's Law. Trans/Form/Ação, (São Paulo), v.29(2), 2006, p.241-248.

- ABSTRACT: Hume's Law, according to which an ought cannot result from an is, and its reciprocal, according to which an is cannot result from an ought, occupy 
salient positions in discussions on metaethics. In this paper I will show logical relations between distinct formulations of Hume's Law and of its reciprocal. I will show, also, how these formulations are related to theses sustained by important thinkers such as Poincaré, Nelson, Jörgensen and Hare.

- KEYWORDS: Hume's Law; reciprocal of Hume's Law; metaethics; Poincaré; Nelson; Jörgensen; Hare.

\section{Referências bibliográficas}

HARE, R. M. A linguagem da moral. São Paulo: Martins Fontes, 1996.

HUME, D. Tratado da natureza humana. São Paulo: UNESP: Imprensa Oficial do Estado, 2000.

JÖRGENSEN, J. Imperatives and logic. Erkenntnis, v. VII, p. 288-296, 1938.

KELSEN, H. Teoria geral das normas. Porto Alegre: Fabris, 1986.

KELSEN, H. Teoria pura do direito. $6^{a}$ edição. São Paulo: Martins Fontes, 1998.

LEWIS, C. S. A abolição do homem. São Paulo: Martins Fontes, 2005.

RABOSSI, E. Dialogo, falacias y retorica. El caso de la falacia naturalista. Manuscrito, v. XXV, n. 2, p. 353-380, 2002.

RESTALL, G.; RUSSELL, G. Barriers to implication. In: PIGDEN, C. Hume and 'is' and 'ought': new essays. Rochester: Rochester University Press, no prelo. 17p.

ROSS, A. Imperatives and logic. Theoria, v. 7, p. 53-71, 1941. 